\title{
Uso da papaína em feridas por enfermeiros da área cirúrgica de um Hospital Universitário
}

\section{Use of papain in wounds by nurses from the surgical area of a University Hospital}

\author{
Andressa de Souza Tavares' • Graciete Saraiva Marques² Mayse Carvalho do Nascimento $^{3}$ \\ Fernanda Rocha Rodrigues ${ }^{4} \bullet$ Rodrigo Costa Soares Savin $^{5} \bullet$ Norma Valéria Dantas de Oliveira Souza $^{6}$
}

\begin{abstract}
RESUMO
O cuidado com feridas constitui atividade importante no cotidiano dos enfermeiros e requer conhecimentos atualizados para intervenção segura. Dentre as terapias tópicas no tratamento de feridas, destaca-se papaína com fácil aplicabilidade e eficácia. Objetivou-se identificar o perfil sociodemográfico dos enfermeiros da área cirúrgica e descrever a indicação da papaína por esses profissionais. Estudo exploratório-descritivo, abordagem quantitativa, realizado com 33 enfermeiros cirúrgicos de um hospital universitário do Rio de Janeiro, abril a junho de 2017, com aplicação de questionário abordando perfil dos enfermeiros e indicação e uso da papaína. A seguir, foram elaborados 2 instrumentos: um alicerçado no levantamento bibliográfico sobre utilização da papaína e um Barema para avaliar respostas obtidas. Os dados foram coletados, agrupados por semelhança, analisados, e posteriormente inseridos no instrumento de avaliação. Foram encontrados $63,6 \%$ dos enfermeiros como residentes e plantonistas, e 28 (84,8\%), confirmaram usar a papaína em feridas. Destes, 67,8\% indicaram a papaína considerando a ação farmacológica. Não houve consenso para emprego nas fases de cicatrização e $82,1 \%$ afirmaram usar equipamento de proteção individual durante o procedimento. Concluiu-se que apesar do uso da papaína pelos enfermeiros, não há consenso na utilização e indicação, o que reforça necessidade de estratégias educativas de atualização para os mesmos.
\end{abstract}

Descritores: Papaína; Cicatrização; Enfermagem cirúrgica.

\begin{abstract}
The use of papain in wounds by surgical nurses of an University Hospital. Wound care is an important activity in the daily routine of nurses and requires up-to-date knowledge for safe intervention. Among the topical therapies in the treatment of wounds, the papain stands out for its easy applicability and effectiveness. The objective was to identify the sociodemographic profile of nurses in the surgical area and to describe the indication of papain by these professionals. An exploratory-descriptive study, a methodological approach, performed with 33 surgical nurses from a university hospital in Rio de Janeiro, from April to June 2017, with the application of a questionnaire addressing nurses' profile and indication of the use of papain. Next, two instruments were elaborated: one based on the bibliographical survey on the use of papain and a Barema to evaluate the answers obtained. The data were collected, grouped by similarity, analyzed, and later, inserted in the evaluation instrument. A total of $63.6 \%$ of nurses were found as residents and attendees, and 28 (84.8\%) confirmed using papain in wounds. Of these, $67.8 \%$ indicated papain considering the pharmacological action. There was no consensus for use in the healing phases and $82.1 \%$ stated that they used personal protective equipment during the procedure. It was concluded that despite the use of papain by nurses, there is no consensus on the use and indication which increases the need for educational strategies to update them.
\end{abstract}

Keywords: Papain; Healing; Surgical nursing.

'Enfermeira especialista em Enfermagem Cirúrgica na modalidade residência HUPE/UERJ. E-mail: tavaresenfI988@gmail.com

${ }^{2}$ Mestre. Estomaterapeuta. Enfermeira chefe da Seção Cirurgia Plástica do Hospital Universitário Pedro Ernesto CCHUPE/UERJ. Membro da Comissão de Curativos do Hospital Universitário Pedro Ernesto CCHUPE/UERJ. E-mail: graciesmar@gmail.com

${ }^{3}$ Estomaterapeuta. Coordenadora da Comissão de Curativos do Hospital Universitário Pedro Ernesto CCHUPE/UERJ. Doutoranda em Enfermagem pela ENF/ UERJ. Professora colaboradora do Curso de Pós-graduação em Enfermagem em Estomaterapia da ENF/UERJ. E-mail: daysecnascimento@hotmail.com ${ }^{4}$ Estomaterapeuta. Membro da Comissão de Curativos do Hospital Universitário Pedro Ernesto CCHUPE/UERJ. E-mail: ferocha60@yahoo.com.br ${ }^{5}$ Enfermeiro especialista em Enfermagem Cirúrgica na modalidade residência HUPE/UERJ. E-mail: rodrigosavin@yahoo.com.br

${ }^{6}$ Professora Associada do Departamento de Enfermagem Médico-Cirúrgica da ENF/UERJ.Professora Permanente da Pós-graduação Stricto Senso da ENF/UERJ. Coordenadora do Curso de Pós-graduação em Enfermagem em Estomaterapia da ENF/UERJ.E-mail:norval_souza@yahoo.com.br 


\section{INTRODUÇÃO}

O cuidado com as feridas constitui uma das atividades importantes no cotidiano dos enfermeiros, devendo, no contexto de suas competências profissionais, avaliar e prescrever os cuidados e o tratamento mais adequado. Ao avaliar criteriosamente a ferida, o enfermeiro deve ter uma observação holística e considerar todos os fatores individuais que podem interferir diretamente no processo de cicatrização, devendo ter conhecimento da fisiopatologia e dos fatores que aceleram ou retardam a cicatrização ${ }^{(1-3)}$.Com o avanço da tecnologia na área da saúde, novas terapias tópicas vêm sendo incorporadas para auxiliar na prevenção e tratamento de feridas. Entre essas, a papaína, que começou a ser usada por profissionais mundialmente desde a década de 50 e no Brasil, desde 1983 com sua prática reconhecida ${ }^{(4,5)}$.

A papaína provém do látex do fruto verde do mamoeiro (carica papaya), comumente encontrado no Brasil e trata-se de uma mistura complexa de enzimas proteolíticas e peroxidases que auxilia na remoção do tecido desvitalizado, atua como desbridante enzimático, bactericida, bacteriostático, anti-inflamatório, estimula a força tênsil, e ainda, proporciona alinhamento das fibras de colágeno para obtenção de cicatrização mais uniforme. Pode ser utilizada em lesões com diferentes etiologias e fases do processo de cicatrização com excelentes resultados, em diversas faixas etárias ${ }^{(4-7)}$.

A forma de apresentação da papaína foi aperfeiçoando-se ao longo dos anos, sendo em forma in natura (polpa do mamão verde), em pó, gel, creme, creme associado à ureia e/ou clorofila e spray. Embora o uso de papaína venha sendo recomendado em nível nacional há mais de três décadas, em instituições públicas e privadas, estudos indicam que ainda não há consenso entre os enfermeiros quanto às indicações de sua utilização, apresentação e tempo de duração da solução após a diluição( ${ }^{(8-11)}$.

Um dos desafios para o uso da enzima é a manutenção de sua estabilidade, bem como sua aplicação e concentração adequada. $\mathrm{Na}$ forma de pó, a papaína deve ser preparada imediatamente antes do curativo e utilizada, pelo fato de ser uma enzima que sofre fácil deterioração, a papaína deve ser mantida em lugar fresco, seco, protegido e ventilado. Em associação com outras substâncias, a papaína exige atenção do profissional que está manipulando, pois é inativada ao reagir com agentes oxidantes como o ferro, o oxigênio, derivados de iodo, água oxigenada e nitrato de prata, luz e calor ${ }^{(6,10,12)}$.

Um fato importante relacionado à manipulação da papaína é de que por ser uma enzima de elevado poder proteolítico, deve ser manipulada com equipamentos de proteção individual (EPIs), pois pode acarretar danos decorrentes da inalação de suas partículas. No Brasil não há dados epidemiológicos nem registros oficiais nos órgãos reguladores sobre reações alérgicas relacionadas ao uso de formulações que contém papaína ${ }^{(10-12)}$.

Lina Monetta foi a primeira enfermeira brasileira a publicar estudos relacionados à efetividade da papaína, utilizando inicialmente a polpa do mamão verde in natura diretamente sobre a lesão, sem um processamento anterior da enzima ${ }^{(13,14)}$.

A instituição trabalhada no estudo, hospital universitário localizado no município do Rio de Janeiro, tem uma Comissão de Curativos composta por estomaterapeutas, as quais indicam a papaína como tratamento tópico em feridas nos pacientes de diferentes faixas etárias e com diversos tipos de lesões após avaliação. Cabe salientar que o produto é manipulado e dispensado pelo Serviço de Farmácia do hospital, adicionado ao pó silicato de magnésio, veículo de incorporação e agente estabilizante, nas concentrações: $2 \%, 4 \%, 6 \%, 10 \%, 15 \%$ e $30 \%{ }^{(15)}$.

Considerando a necessidade do conhecimento do enfermeiro diante do uso e da aplicação da papaína, elaborou-se o seguinte problema de pesquisa: como ocorre o uso da papaína em feridas por enfermeiros da área cirúrgica de um hospital universitário? No sentido de ampliar o conhecimento dos enfermeiros acerca da enzima, do consenso ou não para sua indicação, além de contribuir para maior segurança no seu uso por esses profissionais, propôs-se como objetivos: identificar o perfil sociodemográfico dos enfermeiros da área cirúrgica e descrever a indicação da papaína por esses profissionais.

\section{MÉTODO}

Trata-se de um estudo exploratório-descritivo, com abordagem quantitativa. $O$ cenário do estudo abrangeu unidades de internação cirúrgicas de um hospital universitário localizado no município do Rio de Janeiro. A pesquisa investigou enfermeiros lotados em 8 unidades de internação cirúrgica: supervisores de enfermagem cirúrgica, docentes e residentes do $1^{\circ}$ e $2^{\circ}$ ano do curso de especialização do programa enfermagem cirúrgica. $O$ critério de inclusão utilizado foi Residente de Enfermagem dos Programas de Clínica Cirúrgica; e o de exclusão foi de residentes de enfermagem que estivessem em férias ou licença durante o período de coleta.

Os requisitos éticos propostos pela Resolução $\mathrm{n}^{\circ}$ 466/I 2 foram respeitados, observando-se a livre aceitação dos sujeitos em participar da pesquisa, bem como assinatura do Termo de Consentimento Livre e Esclarecido, sob $n^{\circ}$ de parecer 2.013.490, CAAE 667627I7.0.0000.5259.

A coleta de dados foi realizada de abril a junho de 2017, mediante aplicação de questionário com questões semiabertas, composto por 7 perguntas, caracterizando os participantes enfermeiros ( $I^{a}$ parte), bem como o conhecimento dos mesmos acerca da utilização ou não da 
papaína ( $2^{\mathrm{a}}$ parte). Os dados foram coletados, agrupados por respostas semelhantes e analisados, sendo posteriormente, inseridos no instrumento de avaliação. A seguir, foram elaborados dois instrumentos: o primeiro com as 5 indicações para utilização da papaína em feridas; alicerçados em levantamento bibliográfico, conforme ilustrado na tabela I. O segundo instrumento foi um Barema a fim de avaliar as respostas obtidas no questionário e subsidiar a interpretação do instrumento anterior.

Os dados coletados foram analisados e pontuados no respectivo Barema, tendo como base o instrumento com as 5 indicações e utilizações propostas. Compreendemos que o item I "AÇÃO FARMACOLÓGICA DA ENZIMA", seja de maior importância no que diz respeito à utilização da papaína. Levou-se em consideração que os enfermeiros devem ter relevantes conhecimentos sobre aspectos farmacológicos e propriedades da enzima. Neste sentido, a ação farmacológica foi classificada como item que deve ser mencionado em todas as respostas e, desta forma, o BAREMA foi pautado nas seguintes atribuições de pontuação: excelente, muito bom, bom, razoável, incompleto, inaceitável.

\section{RESULTADOS}

Da população prevista de 43 enfermeiros do cenário cirúrgico dessa instituição, houve 10 exclusões, relacionadas a férias, licenças médicas e a não resposta ao questionário, totalizando 33, caracterizados assim: 05 chefes de seção, 10 plantonistas/diaristas, 5 supervisores, 01 líder, 0 I docente e II residentes.

\section{TABELA 1 - Indicações e utilizações da papaína no tratamento de feridas baseado em levantamento bibliográfico. Rio de Janeiro, 2017}

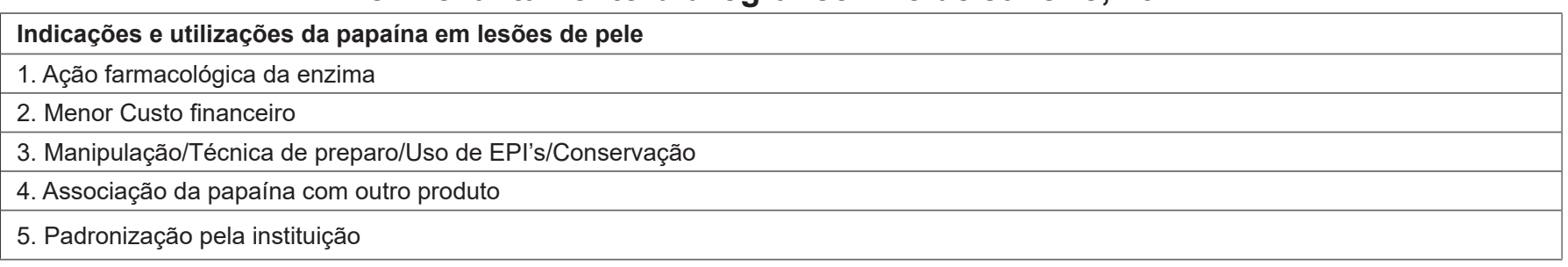

Fonte: Dados dos autores

TABELA 2 - Caracterização dos enfermeiros $(n=33)$ que atuam nas unidades cirúrgicas de um Hospital Universitário. Rio de Janeiro, 2017

\begin{tabular}{|c|c|c|}
\hline VARIÁVEIS & $\mathbf{N}$ & $\%$ \\
\hline \multicolumn{3}{|l|}{ Sexo: } \\
\hline Feminino & 28 & $84,8 \%$ \\
\hline Masculino & 05 & $15,2 \%$ \\
\hline \multicolumn{3}{|l|}{ Faixa Etária: } \\
\hline 23 a 33 anos & 14 & $42,4 \%$ \\
\hline 34 a 43 anos & 11 & $33,3 \%$ \\
\hline 44 a 48 anos & ---- & $-\cdots$ \\
\hline 49 a 64 anos & 08 & $24,3 \%$ \\
\hline \multicolumn{3}{|l|}{ Tempo de exercício profissional: } \\
\hline Até 1 ano & 05 & $15,1 \%$ \\
\hline 1 a 5 anos & 06 & $18,2 \%$ \\
\hline 6 a 10 anos & 06 & $18,2 \%$ \\
\hline 11 a 15 anos & 06 & $18,2 \%$ \\
\hline 16 a 20 anos & 02 & $6,1 \%$ \\
\hline$>$ de 20 anos & 08 & $24,2 \%$ \\
\hline \multicolumn{3}{|l|}{ Cargo que ocupa na instituição: } \\
\hline Chefe de Seção & 05 & $15,1 \%$ \\
\hline Plantonista & 10 & $30,3 \%$ \\
\hline Supervisor & 05 & $15,1 \%$ \\
\hline Líder & 01 & $3,1 \%$ \\
\hline Residente & 11 & $33,3 \%$ \\
\hline Docente & 01 & $3,1 \%$ \\
\hline \multicolumn{3}{|l|}{ Maior titulação: } \\
\hline Especialização (Em curso e/ou concluída) & 27 & $81,8 \%$ \\
\hline Mestrado & 5 & $15,1 \%$ \\
\hline Doutorado & 1 & $3,1 \%$ \\
\hline \multicolumn{3}{|l|}{ Outro vínculo empregatício: } \\
\hline Sim & 14 & $42,4 \%$ \\
\hline Não & 19 & $57,6 \%$ \\
\hline \multicolumn{3}{|l|}{ Tempo de exercício profissional na instituição: } \\
\hline Menos de 1 ano & 05 & $15,2 \%$ \\
\hline 1 a 5 anos & 08 & $24,2 \%$ \\
\hline 6 a 10 anos & 05 & $15,2 \%$ \\
\hline 11 a 15 anos & 06 & $18,1 \%$ \\
\hline 16 a 20 anos & 02 & $6,1 \%$ \\
\hline$>$ de 20 anos & 07 & $21,2 \%$ \\
\hline
\end{tabular}


Como evidenciado na Tabela 2, os enfermeiros participantes do estudo são, majoritariamente do sexo feminino, 28 (84,8\%), com faixa etária variando entre 23 e 64 anos.

$\mathrm{Na}$ mesma tabela I, pode-se fazer um comparativo entre a faixa etária e o cargo que ocupa na instituição, onde se evidenciam enfermeiros entre 23 e 33 anos: 14 (42,4\%), ocupam cargos de residentes: I I (33,3\%) e plantonistas: $10(30,3 \%)$. No estudo houve uma predominância desde enfermeiros recém-formados até 10 anos de profissão. Em contrapartida, os enfermeiros de 34 a 64 anos: 19 (57,6\%), possuem mais de 10 anos de exercício profissional. Estes ocupam cargos de supervisores, docentes e chefes de seção. Obteve-se uma grande quantitativo de enfermeiros com Especialização (em curso e/ ou concluída): 27 (8I,8\%), e com relação ao tempo de exercício profissional na instituição houve variedade de resultados, com 08 enfermeiros $(24,2 \%)$ de $I$ até 5 anos e outros $7(21,2 \%)$ com mais de 20 anos de prática institucional. E ainda, I4 enfermeiros $(42,4 \%)$ responderam que possuem outro vínculo empregatício. Identificado que 3 I enfermeiros $(93,9 \%)$ nunca publicaram algum artigo científico sobre a temática da papaína.

Quanto aos resultados obtidos na $2^{\mathrm{a}}$ parte do questionário, os participantes foram questionados se usavam ou não a papaína, 5 ( $15,2 \%)$ responderam negativamente.

Dando prosseguimento, $28(84,8 \%)$ dos participantes informaram utilizar a papaína no tratamento de feridas, constatando-se que o produto é usado entre esses profissionais na prática da área cirúrgica. Assim, os 28 participantes que responderam que usam o produto foram incluídos como amostra atual (100\%) dessa pesquisa.

Dos 28 participantes que responderam o motivo da indicação pelo qual utilizam a papaína, não houve NENHUMA pontuação excelente (0\%). No entanto, 19 enfermeiros, $67,8 \%$ obtiveram avaliação RAZOÁVEL, ou seja, os participantes responderam pelo menos a ação farmacológica da enzima. Nesse aspecto, avaliou-se a indicação da utilização da papaína e se era correta para os tipos de feridas.

É relevante também salientar que houve uma resposta INCOMPLETA (3,6\%), no qual o participante respondeu a quaisquer outros itens, exceto a ação farmacológica. No que diz respeito à associação com algum outro produto, $28(84,84 \%)$ indicaram positivamente, sendo que $8(28,6 \%)$ destes, relataram que associam a papaína ao Hidrogel.

Com relação à alguns dos cuidados no preparo e manipulação da papaína, a utilização de Equipamento de Proteção Individual (EPI), foi confirmada em 82,1\% dos participantes (23). Quanto à utilização da papaína nas fases das feridas, os resultados apontam para os seguintes dados, demonstrados na tabela 5 :

Ressalta-se que $46,4 \%$ dos enfermeiros indicam o uso da papaína em todas as fases e $35,7 \%$ só em feridas que apresentam necrose e/ou esfacelo. A utilização nas demais fases mantiveram em proporções semelhantes.

No que se refere às concentrações da enzima disponibilizadas neste hospital, $21,4 \%$ dos enfermeiros mencionaram as concentrações da papaína, inclusive relatando o poder de ação destas. Importante ressaltar que houve apenas um relato mencionando todas as concentrações existentes na instituição.

\section{TABELA 3 - Barema dos resultados obtidos referente às indicações para utilização da papaína pelos enfermeiros da área cirúrgica. Rio de Janeiro, 2017}

\begin{tabular}{|c|c|c|}
\hline CRITÉRIOS AVALIADOS & $\mathrm{N}$ & $\%$ \\
\hline EXCELENTE: Responder todos os 5 itens, principalmente ação farmacológica da enzima. & - & $0 \%$ \\
\hline MUITO BOM: Responder sobre a ação farmacológica e pelo menos mais 2 outros itens. & 1 & $3,6 \%$ \\
\hline BOM: Responder sobre a ação farmacológica, e pelo menos mais 1 item. & 7 & $25 \%$ \\
\hline RAZOÁVEL: Responder a pelo menos a ação farmacológica da enzima. & 19 & $67,8 \%$ \\
\hline INCOMPLETO: Responder a quaisquer outros itens exceto ação farmacológica. & 1 & $3,6 \%$ \\
\hline INACEITÁVEL: Aqueles que não responderam, não opinaram e não utilizam o produto. & 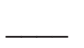 & $0 \%$ \\
\hline TOTAL & & $100 \%$ \\
\hline
\end{tabular}

TABELA 4 - Associação da papaína com outros produtos. Rio de Janeiro, 2017

\begin{tabular}{|c|c|c|c|c|c|c|c|c|}
\hline \multicolumn{3}{|c|}{$\begin{array}{l}\text { Associa a papaína com } \\
\text { algum produto: }\end{array}$} & \multirow{2}{*}{$\begin{array}{l}\text { Hidrogel } \\
8(28,6 \%)\end{array}$} & \multirow{2}{*}{$\begin{array}{c}\text { AGE } \\
\begin{array}{c}\text { (Ácidos graxos } \\
\text { essenciais) }\end{array} \\
3(10,7 \%)\end{array}$} & \multirow{2}{*}{$\begin{array}{c}\text { Soro Fisiológico } \\
\text { à } 0,9 \% \\
3(10,7 \%)\end{array}$} & \multirow{2}{*}{$\begin{array}{c}\text { Creme de } \\
\text { uréia }\end{array}$} & \multirow{2}{*}{$\begin{array}{c}\text { Óxido de zinco } \\
1(3,6 \%)\end{array}$} & Total \\
\hline Sim & 28 & 84,8 & & & & & & 57,2 \\
\hline Não & 5 & 15,1 & 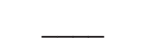 & 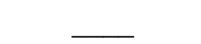 & $\longrightarrow$ & $\longrightarrow$ & $\longrightarrow$ & 21,4 \\
\hline
\end{tabular}


TABELA 5 - Utilização da Papaína nas fases das feridas. Rio de Janeiro, 2017

\begin{tabular}{|c|c|c|c|c|c|c|c|c|c|c|c|c|c|}
\hline \multicolumn{12}{|c|}{ Fases das lesões de pele em que se utilizam a papaína } & \multicolumn{2}{|c|}{ Total } \\
\hline & $\begin{array}{l}\text { las as } \\
\text { ases }\end{array}$ & & $\begin{array}{l}\text { ses de } \\
\text { ulação } \\
\text { efação/ } \\
\text { acelo }\end{array}$ & Teci & nulação & & zação & $\begin{array}{l}\mathrm{De} \\
\mathrm{cor}\end{array}$ & $\begin{array}{l}\text { de da } \\
\text { ração }\end{array}$ & & $\begin{array}{l}\text { oube } \\
\text { har }\end{array}$ & & \\
\hline 13 & $46,4 \%$ & 10 & $35,7 \%$ & 1 & $3,6 \%$ & 1 & $3,6 \%$ & 1 & $3,6 \%$ & 2 & $7,1 \%$ & 28 & $100 \%$ \\
\hline
\end{tabular}

\section{DISCUSSÃO}

Foi evidenciado uma porcentagem expressiva de trabalhadores do sexo feminino $(84,8 \%)$ o que corrobora com a feminização da profissão historicamente mostrada pela relação que existe entre as práticas médicas por meio do tratamento e as da enfermagem, por meio do cuidado, traduzida, por exemplo, pelas ligações que existem entre natureza e legitimidade, entre gênero, classe e poder diante do enfrentamento dos conflitos no trabalho ${ }^{(16,17)}$.

O fato do cenário da pesquisa ser um hospital universitário justifica o caráter formador e qualificador, no qual uma parcela significativa são profissionais em formação ou em especialização, como residentes de diversas especialidades, são qualificados por meio de aprendizagem e treinamento em teoria e habilidades práticas em saúde para aprofundar os conhecimentos científicos. Os residentes ingressam na instituição por meio de concurso público anual, no caso da enfermagem, permanecem 02 anos em diversos campos de práticas de acordo com a especialização. $\bigcirc$ tempo de exercício profissional, o tempo de exercício na instituição e possuir outros vínculos empregatícios, pressupõem que esses enfermeiros já tenham tido contato com o objeto de estudo: uso da papaína em feridas. Em contrapartida, o fato dos enfermeiros residentes serem recém-formados, com vínculo empregatício provisório, pode justificar eles não terem tido ainda essa apropriação com a temática abordada, o que pode aventar a lacuna existente na divulgação de trabalhos baseados na assistência, onde apenas um enfermeiro refere ter publicado artigo sobre a temática ${ }^{(1,3,13)}$.

Cabe realçar que a maioria dos enfermeiros da área cirúrgica $(84,8 \%)$ utiliza a papaína em feridas, apesar de seu uso ainda gerar dúvidas. A aplicação da papaína é referida em estudos como um grande aliado no processo de cicatrização. Quanto às indicações para utilização da papaína, 67,8\% obtiveram resultado RAZOÁVEL, demonstrando que indicam a enzima apenas pela sua ação farmacológica, não atentando para outros aspectos envolvidos nas indicações os quais são indispensáveis e devem ser levadas em conta no que diz respeito ao uso consciente e de forma segura ao paciente $e^{(5,7,10)}$.

E 28 enfermeiros $(84,8 \%)$ utilizam a papaína associada a algum outro produto. Nesse estudo, precisamente, foi evidenciado o hidrogel, o que traz benefícios à lesão levando em consideração a manutenção do meio úmido, com o uso de 2 agentes desbridantes: químico e autolítico. E essa associação eleita, é justificada pela presença de dois tipos de desbridamento, o enzimático e o autolítico, mantendo a lesão com o meio mais úmido, propiciando e intensificando a cicatrização ${ }^{(10-12,14)}$. A associação da papaína a outros produtos ainda é incipiente no contexto brasileiro referente ao tratamento de feridas, o que nos sugere aprofundamento na temática.

$O$ resultado de um pequeno quantitativo de enfermeiros desse hospital não utilizarem a papaína nos curativos de feridas, é diretamente proporcional relacionado ao quantitativo também pequeno de enfermeiros na instituição há menos de I ano, portanto foram excluídos da pesquisa. Cabe destacar aqui que o hospital citado possui Procedimentos Operacionais Padrão (POPs), que ditam ações de enfermagem e servem de respaldo à prática profissional. As concentrações referentes à papaína $(2 \%, 4 \%, 6 \%, 10 \%, 15 \%$ e $30 \%)$ sugeridas e utilizadas na instituição, estão inseridas no POP da mesma a fim de orientar a realização do procedimento e a indicação da terapêutica correta ${ }^{(15)}$.

A fim de analisar a indicação da papaína em feridas pelos enfermeiros da área cirúrgica, foi elaborado um Barema como instrutivo subsidiando avaliar quais são os aspectos utilizados pelos participantes quando indicam a utilização do produto/cobertura, assim foi evidenciado RAZOÁVEL, ou seja, os enfermeiros responderam a pelo menos a ação farmacológica da enzima. E diante do fato de que a ação farmacológica seja o item primordial para que o enfermeiro possa prescrever a papaína, o profissional deve ser capaz de elencar outras indicações para utilização da enzima de forma segura ${ }^{(9,10,13,19)}$.

Em relação a alguns dos cuidados no preparo e manipulação da papaína, 82, $1 \%$ dos enfermeiros utilizam EPIs, evidenciando que possuem conhecimento sobre a manipulação segura, pois a papaína ao ser inalada pode vir a acarretar problemas respiratórios devido seu alto poder proteolítico. Cabe realçar aqui que a papaína exige cuidados especiais em sua manutenção e manipulação, uma vez que é uma enzima instável e exige temperatura ambiente para que não ocorra perda de sua eficácia, além de ser inativada em contato com agentes oxidantes como 
ferro, oxigênio derivados de iodo, nitrato de prata, luz e calor $^{(6-8,10,19,20)}$.

Apesar de indicarem a papaína apenas pela sua ação farmacológica, $46,4 \%$ dos enfermeiros descreveram que a utilizam em todas as fases da lesão, indicando que o uso está sendo feito de forma criteriosa. E no que se refere às concentrações da enzima disponibilizadas na instituição, $21,4 \%$ dos enfermeiros mencionaram as concentrações da papaína, inclusive relatando quanto ao poder de ação destas. A papaína tem indicação da utilização em diversas concentrações, durante todas as fases do processo de cicatrização de feridas, devendo ser direcionada de acordo com a avaliação das características de cada fase da lesão( ${ }^{(7,9,10,21)}$.

O Conselho Federal de Enfermagem, na resolução de $\mathrm{n}^{\circ}$ 50I, de 9 de Dezembro de 2015, regulamenta a competência do enfermeiro para realizar curativos, coordenar e supervisionar a equipe de enfermagem na prevenção e cuidado às feridas, além de outras atribuições. Neste sentido, instrumentalizar o profissional enfermeiro é de grande importância no que diz respeito à segurança e a assistência prestada por esses profissionais ${ }^{(22)}$.

\section{CONCLUSÃO}

O estudo parte do pressuposto em oferecer reflexões aos enfermeiros e profissionais de saúde quanto o uso da papaína em feridas, como uma opção de indicação de cobertura nos diversos tipos e fases da epitelização. No que se refere ao emprego da papaína na área cirúrgica, percebe-se que ainda não há um consenso em sua utilização por parte desses enfermeiros. Portanto, faz-se necessário que o profissional esteja constantemente atualizado e reflita sobre sua prática, promovendo intervenções que ofereçam ao paciente segurança e qualidade. Recomenda-se a construção de uma tecnologia que viabilize a reflexão acerca do uso da papaína, com o intuito de melhorar e racionalizar o uso da enzima, para que venha somar aos protocolos em forma de procedimentos operacionais padrão de Enfermagem (POPs), construídos a partir das evidências, vivência e prática dos profissionais desta instituição.

A implementação e desenvolvimento desse estudo contribuirá para aprofundar a discussão sobre o uso da papaína em feridas por enfermeiros da área cirúrgica. Acredita-se também que poderá contribuir para a produção do conhecimento a ser utilizado na prática assistencial de profissionais que cuidam de pacientes com feridas, principalmente na enfermagem. $E$ ainda, alertar a equipe de enfermagem para a necessidade de uma meIhor assistência nos serviços de saúde, considerando a papaína como terapia tópica de excelente resolutividade como escolha no tratamento, capaz de interferir na qualidade da assistência prestada.

Como limitação, tivemos o próprio cenário do estudo, onde as enfermarias cirúrgicas do hospital passaram por uma junção devido à crise instituída, no qual as especialidades tiveram que ocupar o mesmo espaço físico, impossibilitando, algumas vezes, a coleta de dados.

Recomenda-se divulgar o estudo e propiciar atualização para todos os enfermeiros da instituição, através de tecnologias educativas, tais como: aulas práticas, vídeos, debates sobre a temática e acima de tudo, sedimentar que todos conheçam e se apropriem do POP sobre curativos. Desse modo, o trabalho contribuirá para a produção de conhecimento à comunidade científica, principalmente aos profissionais de saúde 


\section{REFERÊNCIAS}

I.Ferreira AM, Bogamif DDD, Tormena PC. O enfermeiro e o tratamento de feridas: em busca da autonomia do cuidado. Arq Ciênc Saúde. 2008; 15(3): I05-9.

2.Giannini T, Blanck M.Úlceras e feridas - a feridas têm alma - Uma abordagem interdisciplinar do plano de cuidados e da reconstrução estética. Di Livros Editora, Rio de Janeiro, 2014.864p

3. Antoni P. Integração ensino-serviço: qualificação da equipe de enfermagem no tratamento de feridas. In: Anais do V Congresso Brasileiro de Prevenção e Tratamento de Feridas. Revista Enfermagem Atual In Derme 20I5, Ano I5 - No 75 Outubro / Novembro / Dezembro - 2015 p.2I

4.Silva CCR, Rogenski NMB. Uso da papaína: conhecimento de enfermeiros em um hospital da cidade de São Paulo. Rev Estima 2010; 8(1):12-17.

5.Leite AP, Oliveira BGRB, Soares MF, Barrocas DLR. Uso e efetividade da papaína no processo de cicatrização de feridas: uma revisão sistemática. Rev Gaúcha Enferm [Internet]. 2012 [citado 2014 dez. 02];33(3): I98-207. Disponível em: http:// www.scielo.br/pdf/rgenf/ v33n3/26.pdf

6.Silva LM. Efeitos benéficos da papaína no processo terapêutico de lesões de pele. In: Jorge AS, Dantas SRPE.Abordagem multiprofissional do tratamento de feridas. São Paulo:Atheneu; 2003. p. 123-32.

7.Ferreira AM. O uso de papaína no tratamento de feridas. In: Malagutti W(Org). Curativos, estomias e dermatologia: uma abordagem multiprofissional. 3 ed. São Paulo: Martinari, 20I4.p. I35-46.

8.Ribeiro APL, Oliveira BGRB, Soares MF, Barreto BMF, Futuro DO, Castilho SR. Efetividade dos géis de papaína a $2 \%$ e $4 \%$ na cicatrização de úlceras venosas. Revista da Escola de Enfermagem da USP, São Paulo, v. 49, n. 3, p. 394-400, june 2015. ISSN 1980-220X. Disponível em: <https://www.revistas.usp. br/reeusp/article/view/l03220>. Acesso em: 06 june 2018. doi:http://dx.doi.org//0.1590/S0080-623420150000300006.

9.Ferreira AM, Oliveira KA, Vieira LC, Rol JL. Revisão de estudos clínicos de enfermagem: utilização de papaína para o tratamento de feridas. Rev. Enferm. UERJ [Internet] 2005 set-dez I3(3):382-89.Available from: http://www.facenf.uerj.br/ v|3n3/v|3n3al4.pdf

10.Pinto CASO, Green D, Baby AR, Ruas GW. Determination of Papain Activity in Topical Dosage Forms: Single Laboratory Validation Assay. Lat. Am. J. Pharm. 2007;26(5):77 I -5.

I I.Alvarez OM, Fernandez-Obregon A, Rogers RS, Bergamo L, Masso J, Black M. A prospective, randomized, comparative study of collagenase and papain-urea for pressure ulcer debridement. Wounds:A Compendium of Clinical Research \& Practice. 2003; I5(4):293-30I.
12.Weir D, Farley KL. Relative delivery efficiency and convenience of spray and ointment formulations of papain/urea/ chlorophyllin enzymatic wound therapies.JWound Ostomy Continence Nurs 2006 Sep-Oct; 33(5):482-90.

13.Monetta L.A importância da atuação científica do enfermeiro na execução dos curativos feitos com papaína. Rev Paul Enferm. 1990 set-dez; 9(3):83-7.

I4.Monetta, L. Análise evolutiva do processo de cicatrização em úlceras diabéticas, de pressão e venosas com uso de papaína [dissertação de mestrado]. São Paulo: Universidade de São Paulo; 1998.

I5.Marques GS, Nascimento DC, Monteiro AP. Protocolo 4: Estomaterapia. In: Souza RD;Assad LG; Paz AFD (org.) Procedimentos Operacionais - padrão de Enfermagem. Volume II- Parte I. São Paulo:Triunfal, 20 I5. p. I42-6.

16.Beck CLC, Leopardi MT. Da banalização do sofrimento à sua resignificação ética na organização do trabalho. Rev. bras. enferm. [Internet]. 2002 Oct [cited 20I8 May 14] ; 55( 5 ): 601-60I. Available from: http://www.scielo.br/scielo.php?script=sci_arttext\&pid=S0034-7 I 67200200050002 I \&lng=en. http://dx.doi. org/I0.1590/S0034-7|67200200050002I.

17.Amorim, RC. A questão do gênero no ensinar em enfermagem. Rev. Enferm. UERJ, Rio de Janeiro, 2009 jan/mar; 17 (I), 64-8.

18.Velho MTAC, Haeffner L, Santos FG, Silva LC. Residência médica em um hospital universitário: a visão dos residentes. Rev.bras.educ.med. v.36,n. 3, p. 35I-357, Sept. 2012. Available from <http://www.scielo.br/scielo.php?script=sci_ arttext\&pid=SOI00=550220I $2000500009-\& I n g=e n \& n r m-$ iso>. access on 06 June 20/8. http://dx.doi.org//0.1590/ SOI00-550220I2000500009.

19.Silva CCR, Rogenski NMB. Uso da papaína: Conhecimento de enfermeiros em um hospital da cidade de São Paulo. Rev Estima 2010;8(I):12-17.

20.Quiñones D, Alonso S, López R, Sánchez I, Rodríguez F, Fernández $L$, Jerez J. Urticaria de contacto, rinoconjuntivitis $y$ asma bronquial ocupacional por papaína.Allergol Immunopathol (Madr). 1999 Sep-Oct;27(5):273-5.

21. Mandelbaum SH, Mandelbaum MHS, Santis EP. Cicatrização: conceitos atuais e recursos auxiliares - Parte II.Anais Brasileiro de Dermatologia. 2003; 98(5):525-40.

22.Brasil. Decreto n. 94.406/87. Regulamenta a Lei n. 7498, de 25 de junho de 1986. Que dispõe sobre o exercício da Enfermagem e dá outras providências. In: Conselho Federal de Enfermagem (COFEn) [Internet]. Brasília; 1987 [citado 2018 maio 28]. Disponível em: htt p://novo.portalcofen.gov. br/decreto-n-9440687_4l73.html 